\title{
Characterization of Radium Sulphate
}

\author{
Hanna Hedström, ${ }^{1,2}$ Ingmar Persson, ${ }^{3}$ Gunnar Skarnemark, ${ }^{1}$ and Christian Ekberg ${ }^{1,2}$ \\ ${ }^{1}$ Nuclear Chemistry, Department of Chemical and Biological Engineering, Chalmers University of Technology, \\ Kemivägen 4, 41296 Göteborg, Sweden \\ ${ }^{2}$ Industrial Materials Recycling, Department of Chemical and Biological Engineering, Chalmers University of Technology, \\ Kemivägen 4, 41296 Göteborg, Sweden \\ ${ }^{3}$ Department of Chemistry, Swedish University of Agriculture, SLU, Box 7015, 75007 Uppsala, Sweden
}

Correspondence should be addressed to Hanna Hedström; k02heha@gmail.com

Received 11 January 2013; Accepted 2 April 2013

Academic Editor: Subhash Chandra Tripathi

Copyright (C) 2013 Hanna Hedström et al. This is an open access article distributed under the Creative Commons Attribution License, which permits unrestricted use, distribution, and reproduction in any medium, provided the original work is properly cited.

This paper examines the crystal structure of radium sulphate and compares its structure to barium sulphate, strontium sulphate, and lead sulphate. The radium sulphate powder was measured by both powder X-ray diffraction and EXAFS. The unit cell was determined to be orthorhombic, belonging to the Pnma (no. 62) space group with the cell parameters $a=9.07 \AA, b=5.52 \AA$, $c=7.28 \AA$, and $V=364.48 \AA^{3}$. These data support the fact that radium sulphate is isostructural with barium, strontium, and lead sulphate. The bond distances were determined using EXAFS. The mean Ra-O and S-O bond distances were found to be 2.96(2) $\AA$ and 1.485(8) $\AA$, respectively, and the Ra-O-S bond angle was $127(2)^{\circ}$. Findings of EXAFS data are quite consistent and support the XRD data. These findings show that it is possible for radium to coprecipitate with barium, strontium, and lead in sulphate media to form a substitutional solid solution.

\section{Introduction}

There are many crystals that are isostructural; that is, they have the same space groups, and the atoms of the compound are placed in an identical way in the unit cells. For two compounds to form a substitutional solid solution they must be isostructural [1]. The coprecipitation of radium, barium, and strontium is believed to take place due to the formation of a substitutional solid solution. To be able to determine whether this is true or not it is necessary to make further investigations of the structural parameters of radium sulphate and compare them with those reported for barium, strontium, and lead(II)sulphate. These facts allow for possible coprecipitation between these elements. From the point of, for example, a repository for used nuclear fuel, radium release seems to dominate the radiotoxicity to man in a longer time perspective [2]. Thus, if coprecipitation with, for example, barium occurs, the released radium levels can be kept low.

The crystal structures of strontium sulphate (celestite), barium sulfate (barite), and lead(II)sulphate (anglesite) are well determined in a series of studies (see Tables S1 and S2 in supplementary material available online at http://dx.doi .org/10.1155/2013/940701). The unit cell parameters of radium sulphate have been determined in powder diffraction study [3] and show that radium sulphate is isostructural with strontium, barium, and lead(II)sulphate.

The crystal structures of barite $\left(\mathrm{BaSO}_{4}\right)$, celestite $\left(\mathrm{SrSO}_{4}\right)$, and anglesite $\left(\mathrm{PbSO}_{4}\right)$ show that the metal ion is surrounded by twelve oxygens from the sulphate ions in a very broad bond distance distribution, (Table S1) [4]. The mean M-O bond distances, 2.826, 2.948, and $2.864 \AA$ for $\mathrm{Sr}, \mathrm{Ba}$, and $\mathrm{Pb}$, respectively, are fit or are slightly longer than expected from the proposed ionic radii [5] for these ions in twelvecoordination and an assumed atomic radius of sulfate oxygen, $1.34 \AA[6], 2.78,2.95$, and $2.83 \AA$, respectively.

In this work the unit cell parameters of radium sulphate have been determined by means of X-ray powder diffraction and the structure around the absorbing radium ion by means of extended X-ray absorption fine structure (EXAFS). No previous studies on radium sulfate have been made using EXAFS 


\section{Materials and Methods}

The radium sulphate $\left(\mathrm{RaSO}_{4}(\mathrm{~s})\right)$ used in the experiments was obtained from the Sahlgrenska University Hospital, Göteborg, Sweden. The radium was in the form of ${ }^{226} \mathrm{RaSO}_{4}(\mathrm{~s})$ and was previously used for the treatment of cervix cancer [7]. In both types of measurements the samples were prepared with great precautions to avoid the contamination of the equipment.

\section{Measurements}

The characterization was performed using two different methods. The bond distances and angels were calculated using EXAFS data, and the unit cell and space group were determined by X-ray powder diffraction.

3.1. EXAFS-Data Collection. EXAFS measurements were performed on solid radium sulphate, using the radium $\mathrm{L}_{3}$ edge. The data were collected at the wiggler beam line I811 at MAX-lab, Lund University, Lund, Sweden, which operated at $1.5 \mathrm{GeV}$ and a maximum current of $250 \mathrm{~mA}$. The EXAFS station was equipped with a Si[311] double crystal monochromator for data collection on the $\mathrm{Ra} \mathrm{L}_{3}$ edge. Higher-order harmonics were reduced by detuning the second monochromator crystal to reflect $40 \%$ of maximum intensity at the end of the scans. The measurement was performed on the Ra $\mathrm{L}_{3}$ edge in transmission mode. Two scans of $60 \mathrm{~min}$. each were averaged. The radium sulfate sample was placed in a metallic container which was then sealed with Mylar film $(\sim 10 \mu \mathrm{m})$.

3.2. EXAFS-Data Analysis. The GNXAS [8-10] program packages were used for the data treatment. The GNXAS code is based on the calculation of the EXAFS signal and a subsequent refinement of the structural parameters. The GNXAS method accounts for multiple scattering (MS) paths, with correct treatment of the configurational average of all the MS signals to allow fitting of correlated distances and bond distance variances (Debye-Waller factors). A correct description of the first coordination sphere of the studied complex has to account for asymmetry in the distribution of the ionsolvent distances. Therefore the $\mathrm{Ra}-\mathrm{O}$ two-body signals associated with the first coordination shells were modeled with $\Gamma$ like distribution functions which depend on four parameters: the coordination number $N$, the average distance $R$, the mean-square variation $\sigma$, and the skewness $\beta$. The $\beta$ term is related to the third cumulant $C_{3}$ through the relation $C_{3}=$ $\beta \sigma^{3}$, and $R$ is the first moment of the function $4 \pi \int g(r) r^{2} d r$. It is important to stress that $R$ is the average distance and not the position of the maximum of the distribution $\left(R_{m}\right)$.

The standard deviations given for the refined parameters are obtained from $k^{2}$ weighted least-squares refinements of the EXAFS function $\chi(k)$ and do not include systematic errors of the measurements. These statistical error estimates provide a measure of the precision of the results and allow reasonable comparisons, for example, of the significance of relative shifts in the distances. However, the variations in

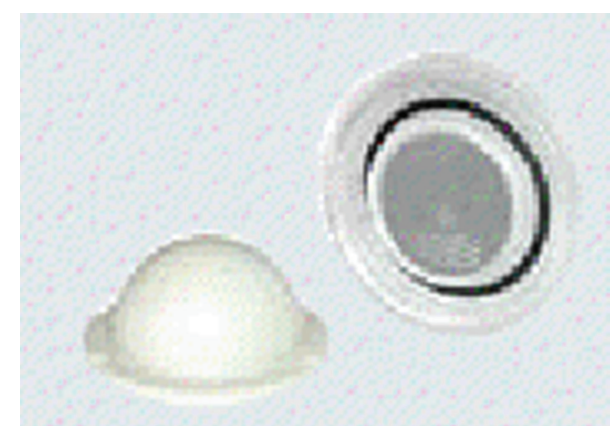

FIGURE 1: Specimen holder made of low background silica plate used for XRD measurements on a small sample size.

the refined parameters, including the shift of the $E_{0}$ value (for which $k=0$ ), using different models and data ranges, indicate that the absolute accuracy of the distances given for the separate complexes is within \pm 0.005 to $0.02 \AA$ for welldefined interactions. The "standard deviations" given in the text have been increased accordingly to include estimated additional effects of systematic errors.

3.3. X-Ray Powder Diffraction. The X-ray intensity data of $\mathrm{RaSO}_{4}$ (s) was collected on a Bruker D2 Phaser powder X-ray diffractometer. The data was collected within the range $10^{\circ} \leq$ $2 \Theta \leq 90^{\circ}$ with $\mathrm{CuK} \alpha$ radiation $(\lambda=1.5418 \mathrm{~nm})$. The specimen was placed on a low background silicon sample holder for small sample amounts and sealed with a low background, airtight specimen holder ring (Figure 1). The sample surface was flattened using a glass slide before the holder was closed. The step scan technique was used at $0.004^{\circ}$ intervals in the $2 \Theta$ area and fixed time of $6 \mathrm{~s}$. A $1 \mathrm{~mm}$ slit was used for the measurement and the plate was set to spin $40 \mathrm{rpm}$. The diffraction intensity was then detected with a Lynxeye (no financial gain was made from using this detector) silicon strip detector.

The data was then evaluated using Celref3 [11].

\section{Results and Discussion}

4.1. X-Ray Powder Diffraction. The X-ray powder diffraction of radium sulphate confirms the result of a previous study [3] that it crystallizes in the orthorhombic space group Pnma (no. 62). The unit cell parameters are somewhat small in this study, $a=9.07, b=5.52$, and $c=7.28 \AA$, compared to $a=9.16$, $b=5.55$, and $c=7.30 \AA$, in the previous study.

There is a strong relationship between the cubic root of the ratio of the unit cell volumes and the difference in mean $\mathrm{M}-\mathrm{O}$ bond distance (Table 1) which makes it possible to calculate the mean $\mathrm{Ra}-\mathrm{O}$ bond distance. The estimated $\mathrm{Ra}-$ O bond distance in $\mathrm{RaSO}_{4}(\mathrm{~s})$ is 2.996 and $3.014 \AA$, based on the data of this study and of the literature [3], respectively. Assuming $n$ atomic radius of $1.34 \AA$ of the sulphate oxygen, the ionic radius of radium will be ca. $1.66 \AA$ in twelvecoordination, which is slightly shorter than that proposed by Shannon, $1.70 \AA$ [5]. 


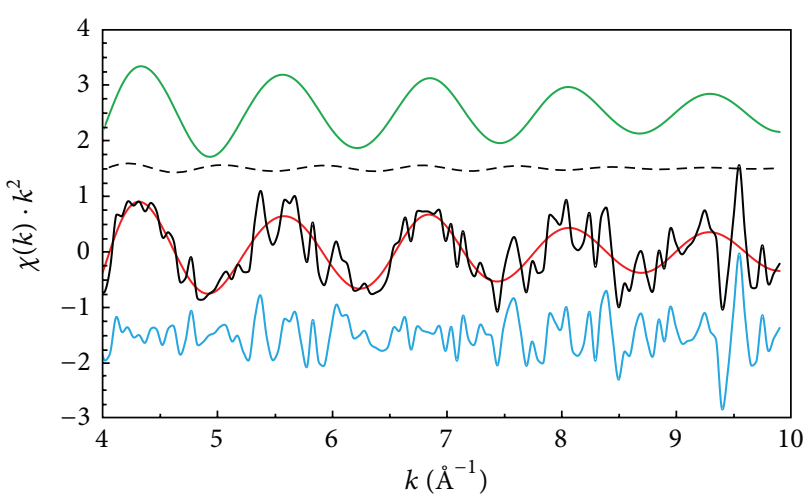

(a)

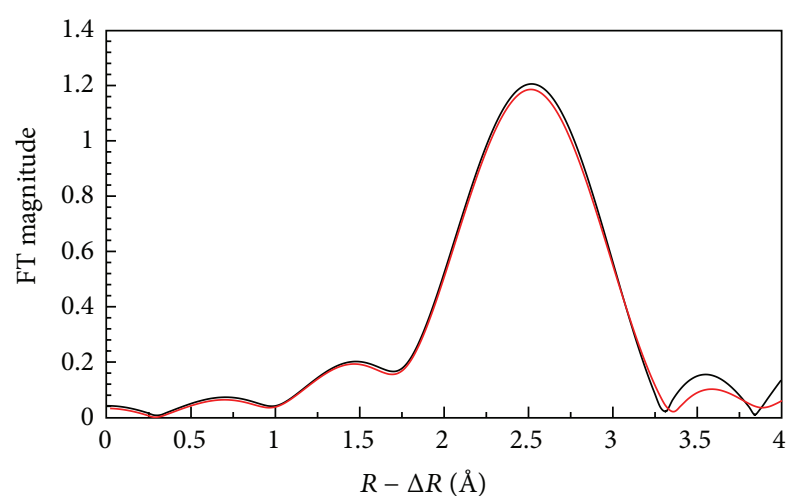

(b)

Figure 2: (a) Fit of EXAFS data and (b) its respective Fourier transform for radium sulphate (red line: model, black line: experimental data, green line: $\mathrm{Ra}-\mathrm{O}$ contribution, dashed black line: Ra. S S contribution, and blue line: residual). The EXAFS data are offset by 1.5 (cumulative) for each contribution. The residual should optimally be a straight line. In this case it is not, which means that there are interactions that are not accounted for in the model.

TABLE 1: (a) Crystallographic data for barite, celestite, radium sulphate, and anglesite, Table S1, and radium sulphate, [3] and this study. (b) Calculation of mean $\mathrm{M}-\mathrm{O}$ bond distances based on the ratio of unit cell volumes, using the mean $\mathrm{Ba}-\mathrm{O}$ bond distance 2.948 Å, Table S2.

(a)

\begin{tabular}{lcccc}
\hline Solid compound & $a / \AA$ & $b / \AA$ & $c / \AA$ & $V / \AA^{3}$ \\
\hline $\mathrm{SrSO}_{4}$ & 8.370 & 5.356 & 6.867 & 307.85 \\
$\mathrm{BaSO}_{4}$ & 8.884 & 5.459 & 7.160 & 347.24 \\
$\mathrm{PbSO}_{4}{ }^{a}$ & 8.488 & 5.395 & 6.961 & 318.76 \\
$\mathrm{RaSO}_{4}{ }^{a}$ & 9.07 & 5.52 & 7.28 & 364.48 \\
$\mathrm{RaSO}_{4}{ }^{\mathrm{b}}$ & 9.16 & 5.55 & 7.30 & 371.12 \\
\hline
\end{tabular}

${ }^{\mathrm{a} T h i s ~ w o r k . ~}{ }^{\mathrm{b}}$ Reference [3].

(b)

\begin{tabular}{lcccc}
\hline Ratio & $\sqrt[3]{V_{\mathrm{X}} / V_{\mathrm{Ba}}}$ & $\begin{array}{c}\text { Exp. } \\
\mathrm{X}-\mathrm{O}\end{array}$ & $\begin{array}{c}\text { Det. } \\
\mathrm{X}-\mathrm{O}\end{array}$ & Diff \\
\hline $\mathrm{SrSO}_{4} / \mathrm{BaSO}_{4}$ & 0.9607 & 2.832 & 2.826 & +0.006 \\
$\mathrm{PbSO}_{4} / \mathrm{BaSO}_{4}$ & 0.9719 & 2.865 & 2.864 & +0.001 \\
$\mathrm{RaSO}_{4}{ }^{\mathrm{a}} / \mathrm{BaSO}_{4}$ & 1.0163 & 2.996 & & \\
$\mathrm{RaSO}_{4}{ }^{\mathrm{b}} / \mathrm{BaSO}_{4}$ & 1.0224 & 3.014 & & \\
\hline
\end{tabular}

${ }^{\mathrm{a}}$ This work. ${ }^{\mathrm{b}}$ Reference [4].

\section{EXAFS}

The EXAFS data are very noisy due to small amounts. It has been possible to perform data treatment even though the errors in the refined parameters are larger than, normally expected. The mean $\mathrm{Ra}-\mathrm{O}$ and $\mathrm{S}-\mathrm{O}$ bond distances were refined to 2.96(2) $\AA, \sigma 2=0.007(2), n=12$, and 1.485(8) $\AA$, $\sigma 2=0.0049(5), n=12$, respectively, and the $\mathrm{Ra}-\mathrm{O}-\mathrm{S}$ bond angle to $127(2)^{\circ}$, which gives a Ra $\cdots S$ distance of $4.03(4)$, $\sigma 2=0.023(5), n=12$. The $\mathrm{S}-\mathrm{O}$ bond distance and the $\mathrm{Ra}-$ $\mathrm{O}-\mathrm{S}$ bond angle are in good agreement with those in $\mathrm{SrSO} 4$, BaSO4, and PbSO4 (references in Table S2). The observed mean $\mathrm{Ra}-\mathrm{O}$ bond distance is slightly shorter than that calculated from the X-ray diffraction data. This is certainly due to the fact that the shorter $\mathrm{Ra}-\mathrm{O}$ distances in the broad bond distance distribution will give a larger contribution to the experimental EXAFS function. This can be treated by refining such a distance with an asymmetric distribution. However, in this case the data quality is not sufficient for such a refinement. The obtained $\mathrm{Ra}-\mathrm{O}$ bond distance from the EXAFS study is therefore reasonable and supports the Xray diffraction data. The fit of the experimental EXAFS data and the Fourier transform are shown in Figure 2.

\section{Conclusions}

The results from the X-ray powder diffraction study confirms that radium sulphate crystallizes in the orthorhombic space group Pnma (no. 62), with the unit cell parameters $a=9.07$, $b=5.52$, and $c=7.28 \AA$. This also confirms that radium sulphate is isostructural with celestite $\left(\mathrm{SrSO}_{4}\right)$, barite $\left(\mathrm{BaSO}_{4}\right)$, and anglesite $\left(\mathrm{PbSO}_{4}\right)$, which explains that radium sulphate can co-precipitate to form substitutional solid solutions with these compounds. In addition the rather flexible 10coordinate structure does allow for small changes in size in the metal ion. The mean $\mathrm{Ra}-\mathrm{O}$ bond distance in radium sulphate has been estimated to ca. $3.00 \AA$ from a comparison with the unit cell volumes of the unit cell of $\mathrm{SrSO}_{4}(\mathrm{~s})$, $\mathrm{BaSO}_{4}(\mathrm{~s}), \mathrm{PbSO}_{4}(\mathrm{~s})$, and $\mathrm{RaSO}_{4}(\mathrm{~s})$. This $\mathrm{Ra}-\mathrm{O}$ bond distance is supported by EXAFS studies.

\section{Acknowledgments}

The authors are grateful to the Swedish Radiation Safety Authority (SSM) and SKIN (Europart 7) for the financial support. Portions of this research were carried out at beamline I811, MAX-lab synchrotron radiation source, Lund University, Sweden. Funding for the beamline I811 project was kindly provided by The Swedish Research Council and The Knut och Alice Wallenbergs Stiftelse. 


\section{References}

[1] B. K. Vaĭnshteĭn, V. M. Fridkin, and V. L. Indebom, Modern Crystallography: Structure of Crystals, Springer, New York, NY, USA, 2000

[2] A. Hedin et al., "Long-term safety for KBS-3 repositories of Forsmark and Laxemar-a first evaluation," SKB TR-06-09, Svensk Kärnbränslehantering AB, 2006.

[3] F. Weigel and A. Trinkl, "Zur Kristallchemie des Radiums. II. Radiumsalze vom Typ $\mathrm{RaXO}_{4}, \mathrm{X}=\mathrm{S}$, Se, Cr, Mo, W,' Radiochimica Acta, vol. 9, pp. 140-144, 1968.

[4] Inorganic Crystal Structure Database 1.4.6 (release: 2011-2); FIZ/NIST.

[5] R. D. Shannon, "Revised effective ionic radii and systematic studies of interatomic distances in halides and chalcogenides," Acta Crystallographica Section A, vol. 32, pp. 751-767, 1976.

[6] J. K. Beattie, S. P. Best, B. W. Skelton, and A. H. White, "Structural studies on the caesium alums, $\mathrm{CsM}^{\mathrm{III}}\left[\mathrm{SO}_{4}\right]_{2} \cdot 12 \mathrm{H}_{2} \mathrm{O}$," Journal of the Chemical Society, Dalton Transactions, no. 10, pp. 2105-2111, 1981.

[7] O. Kjellgren and I. Ragnhult, "Armamentarium for radium treatment of carcinoma of the uterine cervix," Acta Radiologica, vol. 1, pp. 1-5, 1963.

[8] A. Filipponi and A. Di Cicco, "X-ray-absorption spectroscopy and n-body distribution functions in condensed matter. II. Data analysis and applications," Physical Review B, vol. 52, no. 21, pp. 15135-15149, 1995.

[9] A. Filipponi and A. Di Cicco, "GNXAS: a software package for advanced EXAFS multiple-scattering calculations and dataanalysis," Task Quarterly, vol. 4, no. 4, pp. 575-669, 2000.

[10] A. Filipponi, A. Di Cicco, and C. R. Natoli, "X-ray-absorption spectroscopy and n-body distribution functions in condensed matter. I. Theory," Physical Review B, vol. 52, no. 21, pp. 1512215134, 1995.

[11] J. laugier and B. Bochu, "Celref for Windows unit cell refinement program," ENSP/Laboratoire des Materiaux et du Génie Physique, Paris, France. 

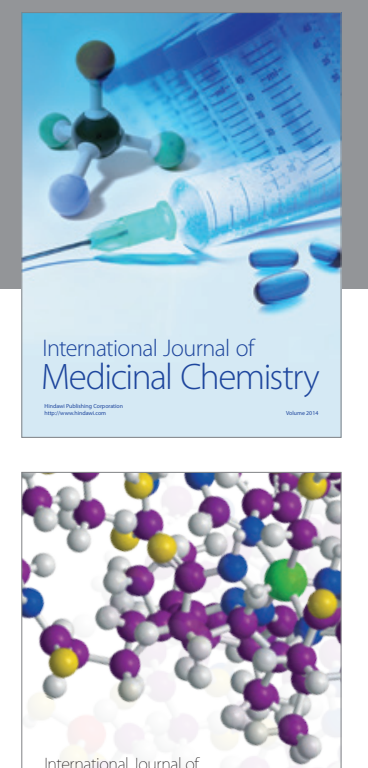

\section{Carbohydrate} Chemistry

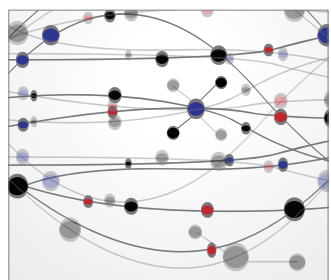

The Scientific World Journal
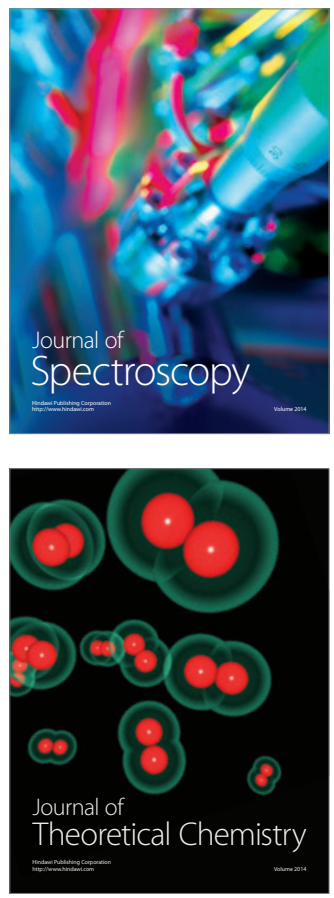
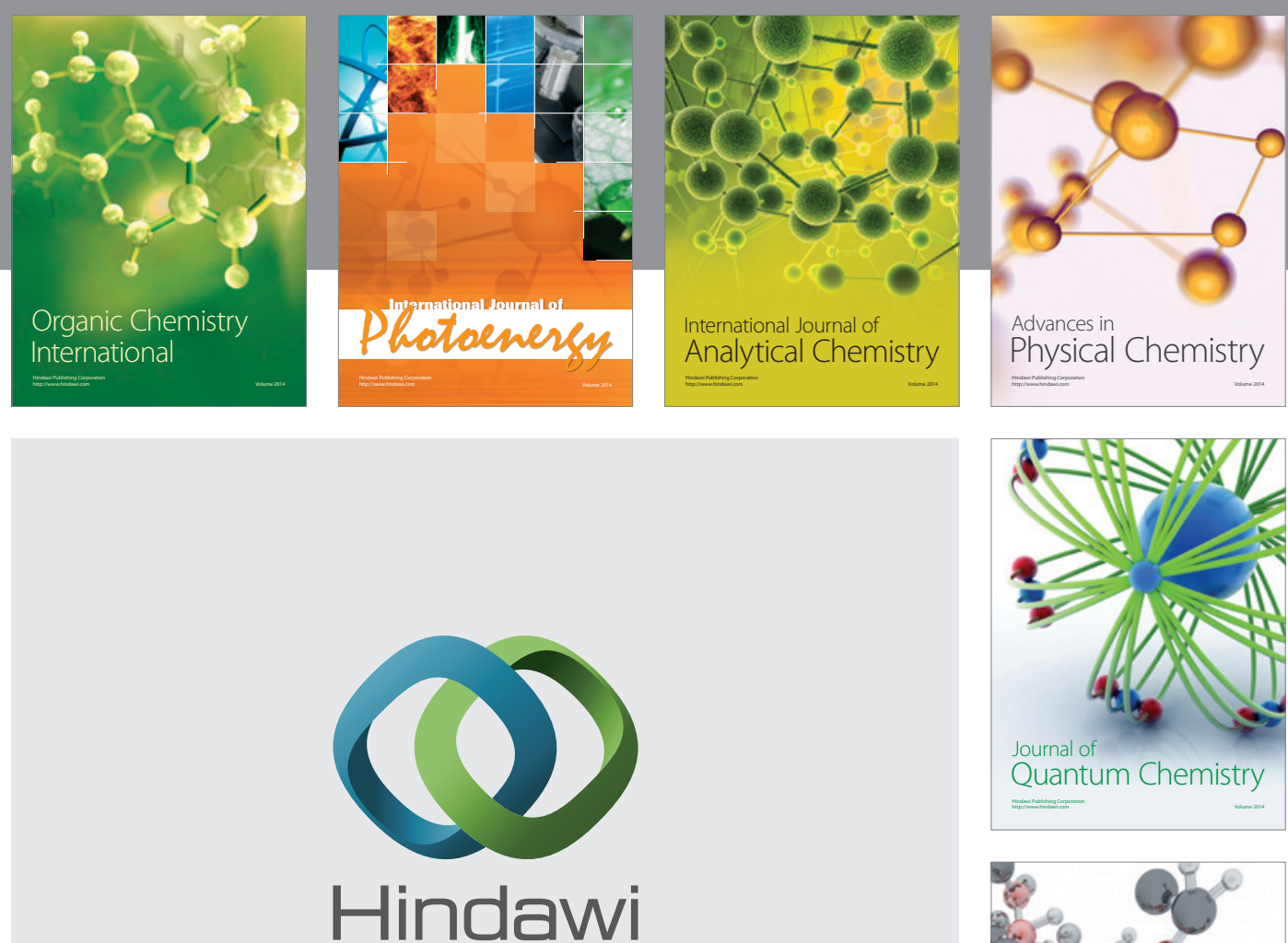

Submit your manuscripts at

http://www.hindawi.com

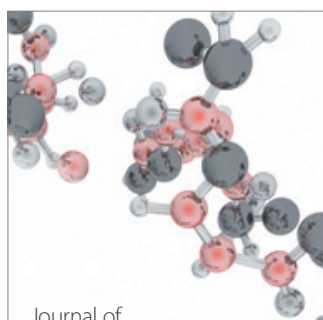

Analytical Methods

in Chemistry

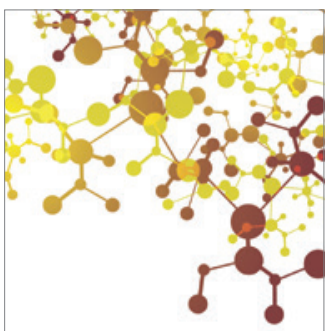

Journal of

Applied Chemistry

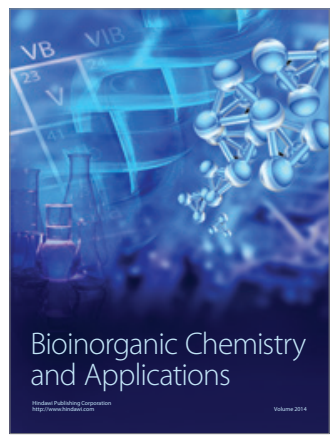

Inorganic Chemistry
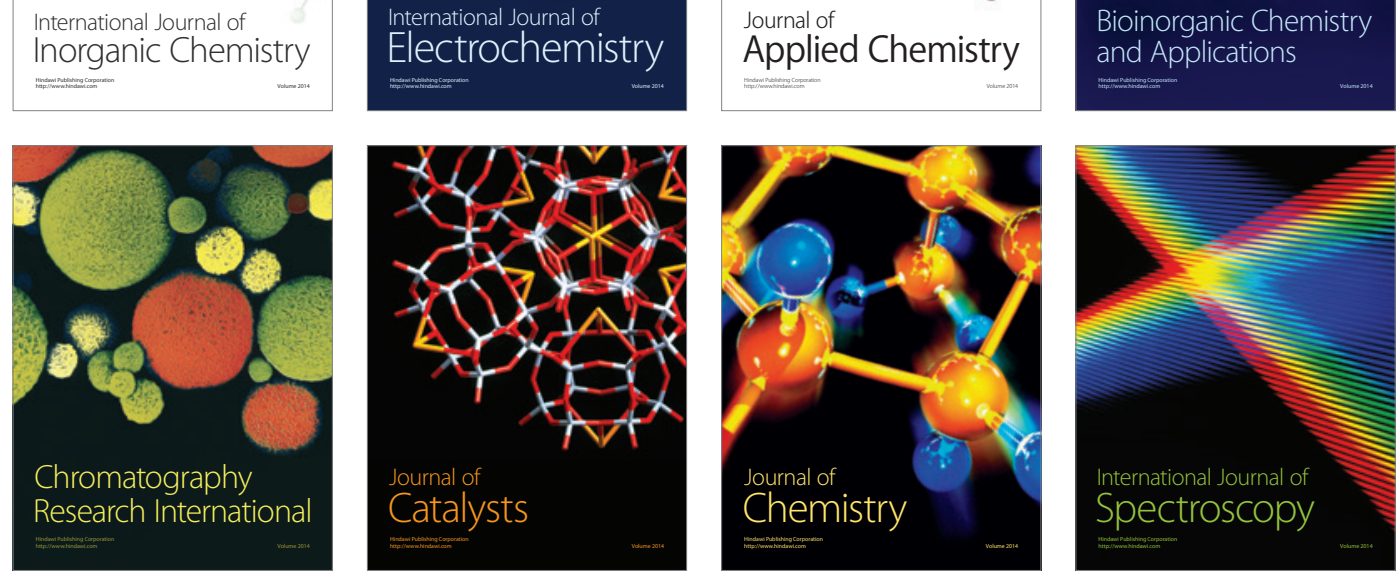